\title{
Association between dietary patterns and hypertension among Han and multi-ethnic population in southwest China
}

\author{
Yuan Ruan ${ }^{1 *} \mathbb{D}$, Yongshou Huang ${ }^{2}$, Qiang Zhang ${ }^{1}$, Shu Qin ${ }^{3}$, Xiaoxia Du ${ }^{3}$ and Yongxin Sun ${ }^{2}$
}

\begin{abstract}
Background: Different dietary patterns and the risks of hypertension in various diet exposures among multi-ethnic population in southwest China remain extremely scarce. The aim of this study is to identify dietary patterns and explore the association between dietary patterns and the risk of hypertension among Han and multi-ethnic population in southwest China.
\end{abstract}

Methods: A representative sample of 3591 participants of Han, and multi-ethnic population were recruited by stratified cluster sampling in Diqing of Yunnan Province, southwest China from September 2012 to January 2013. Participants who were under 18 years old or who could not clearly answer the questions and those who used the anti-hypertensive medication were excluded from this survey. All participants reported their dietary intakes using validated food frequency questionnaires (FFQ), and their blood pressures were measured by standardized procedures. Hypertension was defined as systolic blood pressure (SBP) $\geq 140 \mathrm{mmHg}$ and/or diastolic blood pressure (DBP) $\geq 90 \mathrm{mmHg}$. Dietary patterns were identified by factor analysis with principal component. Logistic regression was used to explore the association between dietary patterns and hypertension.

Results: The overall prevalence of hypertension was 30.5\% among Han and multi-ethnic population in Diqing, Yunnan Province. Three dietary patterns were identified in this study, defined as 'Grassland healthy', Tuber and meat', and 'Fruit and vegetable'. Participants in the 5th quintile of the three dietary patterns were at a lower risk of hypertension compared with those in the 1st quintile. The odds ratio (OR) for the 5th quintile of 'Grassland healthy' pattern, 'Tuber and meat' and 'Fruit and vegetable' was 0.693 (95\% Cl: 0.537-0.893, $p=0.005$ ), 0.678 (95\% Cl: $0.530-0.868$, $p=0.002$ ), 0.759 (95\% Cl: $0.593-0.970, p=0.028)$, respectively. After further adjustment of participants' age, the negative association between the 'Grassland healthy' pattern and the prevalence of hypertension persisted ( $\mathrm{OR}=0.703$, $95 \% \mathrm{Cl}: 0.535-0.924, p=0.012$ ). However, the significant associations between the other two dietary patterns and hypertension disappeared.

Conclusions: The 'Grassland healthy' dietary pattern is associated with lower risk of hypertension, whereas there is no significant associations between the other two dietary patterns and hypertension among Han and multi-ethnic population in Diqing of Yunnan province, southwest China.

Keywords: Dietary pattern, Factor analysis, Multi-ethnic, Hypertension, China

\footnotetext{
*Correspondence: 973686121@qq.com; yncdcyy@163.com

${ }^{1}$ Department of nutrition and food hygiene, Centre for Disease Control and

Prevention (CDC), No.158 Dongsi Street, Kunming 650022, Yunnan, China

Full list of author information is available at the end of the article
}

(c) The Author(s). 2018 Open Access This article is distributed under the terms of the Creative Commons Attribution 4.0 International License (http://creativecommons.org/licenses/by/4.0/), which permits unrestricted use, distribution, and reproduction in any medium, provided you give appropriate credit to the original author(s) and the source, provide a link to the Creative Commons license, and indicate if changes were made. The Creative Commons Public Domain Dedication waiver (http://creativecommons.org/publicdomain/zero/1.0/) applies to the data made available in this article, unless otherwise stated. 


\section{Background}

Hypertension is a worldwide public health concern due to its high prevalence and risk for cardiovascular disease mortality both in developed and developing countries [1, 2 ]. There is $25 \%$ of the world's adult population with hypertension and this figure is likely to increase to $29 \%$ by 2025. It is estimated that by 2025 , the number of individuals with hypertension will be approximately 1.17 billion in developing countries, accounting for three-fourths of the world's hypertensive population [3]. China is one of the world's largest developing counties, with a population of 1.37 billion. According to a nationwide data from 2003 to 2012 , the overall prevalence of hypertension was $26.7 \%$, with the highest in east region (32.6\%) followed by northeast region (31.8\%) [4]. It is well-known that hypertension is a complex interaction of multiple genetic, environmental and behavior factors [5, 6]. Moreover, accumulating evidence suggested that unhealthy diet and lifestyle could play a significant role in the ongoing epidemics of obesity, hypertension and other symptoms of metabolic syndrome [7].

Although the role of diet in the development of hypertension was widely investigated, the majority of researches focus on the intake of individual foods and nutrients. Dietary pattern consisting of a number of food items is widely used as an alternative method to reflect habitual exposure of foods and nutrients as a whole to assess diet and disease relations [8]. Previous study suggest that the vegetarian dietary pattern which comprises foods rich in vegetables, fruits, grains, poultry, legumes, nuts, vegetable oils, soya, and possibly dairy products and/or eggs has been associated with a lower risk for developing hypertension [9]. The western dietary pattern rich in red meat and fats, sugary drinks, fast and processed food is related to a higher risk of hypertension [10]. In China, the traditional dietary greatly changed from low in fat and energy density to high in fat and energy density with the rapid growth of economy [11]. This remarkable nutrition transition may be a better explanation of the high rates of diet related non-communicable disease in the past decades in China [12]. Other studies have already analyzed the relationship between dietary patterns and the prevalence of hypertension, obesity, body weight and the diabetes in China [10, 13-16]. However, dietary patterns may vary between different cultural environments because of the differences in types of food consumed [17]. Therefore, more studies are needed to get further understandings of the association between dietary patterns and hypertension in China, especially in various diet exposures among multi-ethnic population in different places of China.

Yunnan is a relatively undeveloped province in southwest China. The prevalence of hypertension and years of life lost because of hypertension is $24.8 \%$ and 1.5 years, respectively, and hypertension also inflicts a considerable economic burden upon individual households and society in Yunnan [18]. However, issues on dietary and hypertension among Tibetan, Naxi and Lisu multi-ethnic population can't be found. In this study, the dietary pattern and the associations between dietary pattern and hypertension are identified in order to give suggestions for prevention and control of hypertension in this area.

\section{Methods \\ Study population, setting, and design}

This study was a cross-sectional survey with the goal of assessing the association between dietary factors and hypertension among Han and multi-ethnic population in Diqing, which is in the northwest part in Yunnan Province, southwest China. The land area of Diqing is $23,870 \mathrm{~km}^{2}$, with a population of 405,000 . It is the only Tibetan autonomous prefecture in Yunnan Province and the proportion of multi-ethnic population such as Tibetan, Lisu, Naxi is estimated as high as $\mathbf{8 8 . 5 \%}$. Participants were recruited with a stratified cluster sampling method in Diqing in Yunnan Province, southwest China from September in 2012 to January in 2013. All the three counties in Diqing were covered. First, each county was classified into urban area and rural area, and one street was randomly selected from urban areas. In rural area, towns were divided into three strata in terms of household income per capita, and one town was randomly selected from each strata. Then, two communities and two villages were randomly selected from each street or town. In each community or village, 97 households using cluster sampling were involved in this survey, and one member in the household was invited to take part in this survey with informed consent (Additional file 1: Informed consent). To be eligible, an individual had to be living in Diqing at the time of study and for at least 6 months of the previous year, be aged 18 years old or more, and be able to answer the questions without assistance (i.e. no major speech or neurological impairment). If the community or village failed to meet the sample size, they were merged by the nearby community or village to continue to finish this survey. Household replacement was taken due to housing demolition, uninhabited, households change, no response or rejection to this survey, and it was replaced by other one in the neighbor village. The family structure of replacement households was similar to the original household. The replacement percentage was less than 10\%. Finally, a total of 3591 participants had finished the face to face interview and blood pressure measurement at their homes with a valid response rate of $98.4 \%$.

\section{Data collection}

Face to face interviews were conducted by trained and experienced staff from local CDC in a private room at participants' home. Data were collected and managed 
using a pre-tested questionnaire, which was consisted of socio-demographic characteristics, family history of hypertension, physical activity and FFQ about food intake history both frequency of consumption (daily, weekly, monthly, yearly or never) and quantity of intake of a list of foods and beverages in the past 12 months. There were 26 food groups. Finally, they were merged into 20 groups (rice, wheaten food, coarse cereals, tuber, pork, beef and mutton, animal organ, poultry, aquatic products, vegetables, fruits, eggs, yogurt, milk, beans, soy products, cakes, juice and beverage, oil and salt) due to the similarity of nutrient profiles and the low intake of some food groups.

\section{Anthropometric measurement}

Body weight was measured in light indoor clothing without shoes to the nearest $0.1 \mathrm{~kg}$. Height was measured without heavy clothes and shoes to the nearest $0.1 \mathrm{~cm}$. All measurements were repeated three times during the visit by trained physician using a standard protocol and techniques. Body mass index (BMI) was calculated as weight in kilograms divided by height in meters squared. Underweight, normal weight, overweight and obesity were defined as $\mathrm{BMI}<18.5$, 18.5-23.9, 24.0-27.9, and $\geq 28.0 \mathrm{~kg} / \mathrm{m}^{2}$, respectively, according to Chinese standard [16].

\section{Blood pressure measurement}

Blood pressure was measured twice at the house of the participants after a rest of 5 minutes by the trained interviewer using standard mercury sphygmomanometer and appropriate-sized cuff according to a standard protocol, and the blood pressure was recorded in average. The hypertension was defined as an average SBP at least $140 \mathrm{mmHg}$, and/or DBP at least $90 \mathrm{mmHg}$ without any anti-hypertensive medication use [19].

\section{Definitions of variables}

The classification of sex was male and female. Age was divided into four groups: $18-35,36-45,46-55, \geq 56$. The category of ethnicity was classified into four groups: Tibetan, Lisu, Naxi, Han and other. Education level was divided into three groups in terms of years at school: < middle school ( $<9$ years), middle school (9 years) and $>$ middle school ( $>9$ years). BMI was classified into four groups according to Chinese standard: underweight $(\mathrm{BMI}<18.5)$, normal weight $(\mathrm{BMI}=18.5-23.9)$, overweight $(B M I=24.0-27.9)$ and obesity $(B M I \geq 28.0)$. The physical activity level was measured by metabolic equivalents (MET) in minutes per week according to occupation, transportation, housework, and recreational activity, and it was divided into three groups: low ( $\leq 599 \mathrm{MET}$-min/week), moderate (600-2999 MET-min/week), vigorous ( $\geq 3000$ MET-min/week) [20]. Family hypertension history was defined as diagnosis of hypertension in one parent, and it was categorized as yes, no and unknown.

\section{Statistical analysis}

The data were entered in EpiData 3.1 and analyzed by IBM SPSS 20.0 (IBM SPSS Inc., USA). In all, 3591 subjects were included in the study. Demographic characteristics, BMI, physical activity, and family history of hypertension were defined as categorical variables, and the prevalence of hypertension was calculated in each subgroup. Chi-square test was used to determine significant risk factors for hypertension in Table 1.

Dietary patterns were analyzed by factor analysis with principal component based on the 20 food groups from the FFQ. The number of factors retained was determined by eigenvalues $(>1.0)$, the Scree test and the interpretability of factors. Varimax orthogonal rotation was performed to simplify the factor matrix and facilitate data interpretation by generating nonrelated factors. Rotated factor loadings $>0.25$ or $<-0.25$ were considered to significantly contribute to a pattern. The highest factor loadings were considered when identifying a name for each of the dietary patterns. The factor analysis generated three major dietary patterns. Pattern-specific scores were calculated and assigned to each participant, and they were divided into quintiles. Socio-demographic characteristics were described across quintiles in each dietary pattern. Chi-square tests were used to determine if there were any significant differences between the groups of demographic characteristics classified in the 1 st and 5th quintile for a specific dietary pattern.

Associations between each dietary pattern and hypertension were tested by binary logistic regression with potential confounders adjusted. All statistical tests were two-tailed, and a $p$-value $<0.05$ was considered statistically significant.

\section{Results}

\section{Prevalence of hypertension}

The overall prevalence of hypertension aged 18 years old or over among Han and multi-ethnic population in Diqing, Yunnan Province was $30.5 \%$ in our study. The prevalence of hypertension both for men and women was $32.0 \%$ and $29.5 \%$, respectively. The prevalence of hypertension did not significantly differ across sex and ethnicity. People of the youngest age had the lowest prevalence of hypertension. As age increased, prevalence of hypertension also increased ( $p$ $<0.01$ ). In addition, the prevalence of hypertension differed significantly over the groups defined by education, BMI, physical activity and family history (Table 1).

\section{Dietary patterns}

Three major types of dietary patterns, namely 'Grassland healthy', 'Tuber and meat', and 'fruit and vegetable' were 
Table 1 Prevalence of hypertension in Diqing, Yunnan, China $(N=3591)$

\begin{tabular}{|c|c|c|c|c|}
\hline \multirow[t]{2}{*}{ Characteristics } & \multirow[t]{2}{*}{$n$} & \multicolumn{2}{|c|}{ Prevalence of hypertension } & \multirow[t]{2}{*}{$p$-value } \\
\hline & & $\overline{n^{a}}$ & $\%$ & \\
\hline \multicolumn{4}{|l|}{ Sex } & 0.106 \\
\hline Male & 1396 & 447 & 32.0 & \\
\hline Female & 2195 & 647 & 29.5 & \\
\hline \multicolumn{4}{|l|}{ Age } & 0.000 \\
\hline $18-35$ & 1049 & 90 & 8.6 & \\
\hline $36-45$ & 858 & 186 & 21.7 & \\
\hline $46-55$ & 704 & 246 & 34.9 & \\
\hline $56-$ & 980 & 572 & 58.4 & \\
\hline \multicolumn{4}{|l|}{ Ethnicity } & 0.132 \\
\hline Tibetan & 1368 & 479 & 35.0 & \\
\hline Lisu & 562 & 112 & 19.9 & \\
\hline Naxi & 810 & 228 & 28.1 & \\
\hline Han & 551 & 190 & 34.5 & \\
\hline Other & 300 & 85 & 28.3 & \\
\hline \multicolumn{4}{|l|}{ Education } & 0.000 \\
\hline$<$ Middle school & 2248 & 794 & 35.3 & \\
\hline Middle school & 985 & 203 & 20.6 & \\
\hline > Middle school & 358 & 97 & 27.1 & \\
\hline \multicolumn{4}{|l|}{ BMl } & 0.000 \\
\hline Underweight & 266 & 47 & 17.7 & \\
\hline Normal & 2017 & 467 & 23.2 & \\
\hline Overweight & 937 & 374 & 39.9 & \\
\hline Obesity & 371 & 206 & 55.5 & \\
\hline \multicolumn{4}{|l|}{ Physical activity } & 0.000 \\
\hline Low & 2207 & 753 & 34.1 & \\
\hline Moderate & 995 & 254 & 25.5 & \\
\hline Vigorous & 389 & 87 & 22.4 & \\
\hline \multicolumn{4}{|c|}{ Family history of hypertension } & 0.000 \\
\hline Yes & 638 & 213 & 33.4 & \\
\hline No & 2209 & 549 & 24.9 & \\
\hline Unknown & 744 & 332 & 44.6 & \\
\hline
\end{tabular}

$n$ : the number of participants in each subgroup. $n^{\text {a }}$ : the number of participants diagnosed as hypertension in each subgroup. Chi-square tests were used to determine if there were any significant differences between hypertension and each subgroup

identified, which totally explained $25.4 \%$ of the variance in food intake. The first type was highly relative with yogurt, soy products and eggs. The second type characterized by high intake of tuber, beef and mutton, and pork. The third type was highly correlated with fruits and vegetables. The factors loading for each dietary pattern were presented in Table 2. When demographic characteristics of subjects across quintile categories of each dietary pattern scores were analyzed, we found that participants who were younger and had higher level of education adhered more to the 'Grassland healthy' pattern. The male, younger, Tibetan were more likely to involve in the 'Tuber and meat' pattern. Participants who were male, younger, Naxi and participants had lower level of education were more likely in the 'Fruit and vegetable' pattern, which was presented in Table 3 .

\section{Dietary patterns and hypertension}

The prevalence of hypertension decreased across quintiles of three dietary patterns. As the scores of 'Grassland healthy', 'Tuber and meat' and 'Fruit and vegetable' dietary pattern increased, the prevalence of hypertension decreased from 33.7 to $23.3 \%, 35.1 \%$ to $26.7 \%, 34.4 \%$ to $28.4 \%$, respectively, which was shown in Table 4 .

Participants in the 5th quintile of scores for the three dietary patterns were at a lower risk of hypertension. The OR comparing the 1st quintile of scores for the three dietary patterns quintiles to the highest was 0.693 (95\% CI: 0.537-0.893), 0.678 (95\% CI: 0.530-0.868), 0.759 (95\% CI: 0.593-0.970), respectively, after adjusting for sex, ethnicity, education level, BMI, physical activity and family history of hypertension. After further adjustment for age, the association between 'Grassland healthy' pattern and hypertension was appreciably attenuated. The negative correlations between the other two dietary patterns and hypertension were disappeared in this study. Table 5 shows the adjusted OR and its $95 \%$ CI for hypertension in quintiles of different dietary patterns.

\section{Discussion}

In the present study, we report the prevalence of hypertension and risk factors of hypertension in univariate analysis which were used for further adjustment. Then we identify three major dietary patterns and examine their associations with hypertension. Thus, we divide the discussions into three parts as follows. Firstly, the overall prevalence of hypertension among Han and multi-ethnic groups aged 18 years and above was 30.5\% in Diqing in Yunnan Province, southwest China, whereas the prevalence of hypertension was $21.5 \%$ among Chinese residents older than 15 years using a systematic review and meta-analysis between 2002 and 2011 from nine provinces of China [21]. And the disparity of this prevalence in southern Zhejiang Province and northeastern Jiling Province in China is $24.6 \%$ [22] and $30.8 \%$, respectively [23]. The prevalence of hypertension in our study is similar with those in northeastern parts of China. Although the differences in methods and study population restrict comparison across studies, the prevalence of hypertension in this study exceeded the results in southern China. Possible explanations for this increase of hypertension prevalence may include the following reasons: first of all, we speculate that the higher prevalence of hypertension is possibly attributed to the environmental factor compared 
Table 2 Factor loading of dietary patterns in Diqing, Yunnan, China $(N=3591)$

\begin{tabular}{|c|c|c|c|}
\hline Food items & $\begin{array}{l}\text { Grassland } \\
\text { healthy }\end{array}$ & $\begin{array}{l}\text { Tuber and } \\
\text { meat }\end{array}$ & $\begin{array}{l}\text { Fruit and } \\
\text { vegetable }\end{array}$ \\
\hline Yogurt & 0.76 & 0.02 & -0.04 \\
\hline Soy products & 0.70 & 0.04 & 0.06 \\
\hline Eggs & 0.65 & -0.10 & 0.22 \\
\hline Milk & 0.53 & 0.13 & -0.13 \\
\hline Coarse cereals & 0.24 & 0.08 & -0.03 \\
\hline Cakes & 0.20 & 0.13 & -0.03 \\
\hline Pork & 0.15 & 0.60 & 0.12 \\
\hline Wheaten food & 0.10 & 0.35 & 0.21 \\
\hline Juice and beverage & 0.08 & 0.09 & 0.07 \\
\hline Aquatic product & 0.06 & 0.03 & 0.09 \\
\hline Oil & 0.05 & 0.02 & -0.16 \\
\hline Rice & 0.04 & 0.06 & 0.02 \\
\hline Tuber & 0.03 & 0.67 & 0.13 \\
\hline Beans & 0.02 & 0.02 & -0.06 \\
\hline Fruits & 0.02 & -0.06 & 0.74 \\
\hline Vegetables & 0.02 & 0.16 & 0.74 \\
\hline Animal organs & 0.00 & 0.00 & -0.04 \\
\hline Salt & -0.02 & 0.02 & 0.20 \\
\hline Beef and mutton & -0.03 & 0.67 & -0.12 \\
\hline Poultry & -0.10 & -0.01 & 0.03 \\
\hline
\end{tabular}

In bold are the rotated factors loading $>0.25$ or $<-0.25$. The three types of pattern explained $11.3 \%, 7.5 \%$ and $6.6 \%$ of the variance in dietary intake, respectively

with the low altitude area. Though we did not collect data on the altitude and climate for individual participant, we inquiry the altitude of the habitat for Han, Tibetan, Naxi, Lisu and other ethnic group in Diqing, southwest China which is about $3300 \mathrm{~m}$ above sea level. We note that the Tibetan living at the highest altitude had a higher prevalence of hypertension than the ethnic group of Lisu living at the lowest altitude. As a previous study revealed, the prevalence of hypertension increased with altitudes [24]. Secondly, the difference is likely due to difficult access to medical care in this undeveloped area. The majority of rural populations do not regularly see a doctor because of their low income, which implies that a large proportion of hypertensive patients were not early diagnosed and they did not receive any medical treatment and control. As previous studies noted, prevalence of hypertension among ethnic minorities varied between $25 \%$ in Hani minority and $64 \%$ in Tibetan in Yunnan Province. However, the rates of hypertension treatment and control were lower in Yunnan. Only $19.9 \%$ hypertensive patients were treated by diet and/or medication, $11.7 \%$ for treatment with medication, and $10.8 \%$ for control [25]. These rates of treatment and control were among the lowest in China. A previous study reported the hypertension treatment and control rates was $48.2 \%, 32.1 \%$, respectively in urban China [26]. Additionally, the prevalence of hypertension we observed in this study was possibly underestimated, because we had excluded the subjects who used anti-hypertension medicine.

Secondly, age, lower education, obesity and family history are related to higher prevalence of hypertension in this study, which is consistent with previous studies [22, 23]. The prevalence of hypertension increases from 8.6 to $58.4 \%$ between 18 and 35 years and $\geq 56$ years. The oldest group has the highest prevalence of hypertension, compared with the youngest group. The previous studies also reported that the prevalence rates of hypertension was $57.7 \%$ ( $\geq 60$ years) and $53.5 \%$ (55-64 years) in southern and northern China, respectively [22, 23]. It appears that age plays a significant role in developing hypertension. Vigorous physical activity is related to lower prevalence of hypertension in our study, and evidence from international studies had further confirmed that physical activity has a favorable effect on blood pressure reduction [27]. However, the prevalence of hypertension did not differ across the various minorities in the present study. Inconsistent with this, a previous multi-ethnic population survey reported that some minorities were associated with a higher prevalence rate of hypertension compared to Han population [28]. Previous studies usually selected different places and various dietary habits for comparison. We assume that the discrepancy of prevalence of hypertension was possibly reduced by the adaptation to local environment and diet among multi-ethnic population living in this area.

Thirdly, we identified three major dietary patterns named the 'Grassland healthy', 'Tuber and meat' and 'Fruit and vegetable' pattern among Han and multi-ethnic population in Diqing, Yunnan Province, southwest China. These three dietary patterns were negatively associated with hypertension after adjustment of sex, ethnicity, education, BMI, physical activity and family history of hypertension. When age was additionally adjusted, the 'Grassland healthy' pattern was inversely correlated with hypertension, while there were no associations between the other two dietary patterns and hypertension. The 'Grassland healthy' pattern characterized by high intake of yogurt, soy products and eggs, which was not similar with traditional diets in south China, characterized by high intake of fruit, pork, poultry, rice, vegetables, aquatic products $[29,30]$. This could be interpreted by ethnic and regional differences. Tibetan and other minorities preferred milk and dairy products in their diet culture, and yogurt was highly available in this pastoral area enriched by fertile grassland. Yogurt is a fermented dairy product. A previous study shows that regular yogurt intake could reduce the risk of cardiovascular disease among hypertensive adults [31]. Egg protein, milk protein, soy protein and 
Table 3 Socio-demographic characteristics of participants across quintiles categories of dietary pattern scores in Diqing, Yunnan, China $(N=3,5$ s91)

\begin{tabular}{|c|c|c|c|c|c|c|}
\hline \multirow{3}{*}{$\begin{array}{l}\text { Demographic } \\
\text { characteristics }\end{array}$} & \multicolumn{2}{|c|}{ Grassland healthy } & \multicolumn{2}{|c|}{ Tuber and meat } & \multicolumn{2}{|c|}{ Fruit and vegetable } \\
\hline & Q1 & Q5 & Q1 & Q5 & Q1 & Q5 \\
\hline & n (\%) & n (\%) & $\mathrm{n}(\%)$ & n (\%) & n (\%) & n (\%) \\
\hline \multicolumn{7}{|l|}{ Sex } \\
\hline Male & $265(37.2)$ & $282(39.3)$ & $245(34.2)$ & $363(50.4)^{* * *}$ & $236(32.9)$ & $312(43.8)^{* * *}$ \\
\hline Female & $448(62.8)$ & $436(60.7)$ & $471(65.8)$ & 357 (49.6) & $482(67.1)$ & $400(56.2)$ \\
\hline \multicolumn{7}{|l|}{ Age } \\
\hline $18-35$ & $164(23.0)$ & $315(43.9)^{* * *}$ & $213(29.7)$ & $239(33.2)^{* * *}$ & $180(25.1)$ & $207(29.1)^{* * *}$ \\
\hline $36-45$ & $186(26.1)$ & $114(15.9)$ & $147(20.5)$ & $178(24.7)$ & $169(23.5)$ & $202(28.4)$ \\
\hline $46-55$ & $148(20.8)$ & $124(17.3)$ & $117(16.3)$ & $159(22.1)$ & 137 (18.6) & 139 (19.5) \\
\hline $56-$ & $215(30.2)$ & $165(23.0)$ & 239 (33.4) & $144(20.0)$ & $232(32.3)$ & $164(23.0)$ \\
\hline \multicolumn{7}{|l|}{ Ethnicity } \\
\hline Tibetan & $238(33.4)$ & $223(31.1)$ & $203(28.4)$ & $332(46.1)^{* * *}$ & $360(50.1)$ & $200(28.1)^{* * *}$ \\
\hline Lisu & $94(13.2)$ & $171(23.8)$ & $114(15.9)$ & $115(16.0)$ & 109 (15.2) & $84(11.8)$ \\
\hline Naxi & $230(32.3)$ & $128(17.8)$ & $182(25.4)$ & $155(21.5)$ & 135 (18.8) & 219 (30.8) \\
\hline Han & $98(13.7)$ & $142(19.8)$ & $154(21.5)$ & $74(10.3)$ & $71(9.9)$ & $137(19.2)$ \\
\hline Other & $53(7.4)$ & $54(7.5)$ & $63(8.8)$ & $44(6.1)$ & $43(6.0)$ & $72(10.1)$ \\
\hline \multicolumn{7}{|l|}{ Education } \\
\hline$<$ Middle school & $515(72.2)$ & $308(42.9)^{* * * *}$ & $462(64.5)$ & $420(58.3)$ & $504(70.2)$ & $434(61.0)^{* *}$ \\
\hline Middle school & $131(18.4)$ & 313 (43.6) & $182(24.5)$ & $231(32.1)$ & $150(20.9)$ & $204(28.7)$ \\
\hline > Middle school & $67(9.4)$ & 97 (13.5) & 72 (10.1) & $69(9.6)$ & $64(8.9)$ & $74(10.4)$ \\
\hline
\end{tabular}

pea protein can reduce systolic blood pressure and diastolic blood pressure among overweight men and women with pre-hypertension or untreated stage I hypertension [32]. The prevalence of hypertension decreased from 33.7 to $23.3 \%$ as the scores of the 'Grassland healthy' pattern increased in our study. This dietary pattern had been identified as a protective factor for developing hypertension after adjustment of confounders. Our finding is consistent with studies in different counties. A study from Taiwan reported that egg and dairy food pattern had a significant lower risk of hypertension [33]. Another study from Pakistan reported that the yogurt pattern was less likely to be associated with hypertension [34]. The 'Tuber and meat' dietary pattern we identified in this study was characterized by high intake of tuber, beef and mutton, and pork. Although this pattern adopters consumed red meat which was widely recognized as a risk factor for hypertension [35], this dietary pattern was appeared to be a protective factor for hypertension in the present study. Accordingly, we further adjusted for age in the multi-variable logistic regression. The correlation between the 'Tuber and meat' pattern and the prevalence of hypertension did not exist, which indicated that the association could be more attributed to participants' age. Compared with the meat pattern which was defined as high intake of chickens, beef, lamb, duck, goose in a previous study [36], the 'Tuber and meat' pattern in the present study was loaded heavily on tuber. The tuber rich in dietary fiber was reported to be inversely associated with obesity and positively associated with underweight [37]. The dietary fiber has the antihypertensive effects as well as the prevention of a number of cardiovascular diseases [38, 39]. The

Table 4 Prevalence of hypertension across quintiles of dietary patterns in Diqing, Yunnan, China $(N=3591)$

\begin{tabular}{|c|c|c|c|c|c|c|c|c|c|c|c|}
\hline \multirow[t]{2}{*}{ Dietary pattern } & \multicolumn{2}{|l|}{ Q1 } & \multicolumn{2}{|l|}{ Q2 } & \multicolumn{2}{|l|}{ Q3 } & \multicolumn{2}{|l|}{ Q4 } & \multicolumn{2}{|l|}{ Q5 } & \multirow{2}{*}{$\begin{array}{l}p \text { for } \\
\text { trend }\end{array}$} \\
\hline & $\mathrm{n}$ & $\%$ & $n$ & $\%$ & $n$ & $\%$ & $n$ & $\%$ & $\mathrm{n}$ & $\%$ & \\
\hline Grassland healthy & 240 & 33.7 & 259 & 36.0 & 234 & 32.4 & 194 & 27.1 & 167 & 23.3 & 0.000 \\
\hline Tuber and meat & 251 & 35.1 & 234 & 32.3 & 225 & 31.3 & 192 & 27.0 & 192 & 26.7 & 0.000 \\
\hline Fruit and meat & 247 & 34.4 & 233 & 32.3 & 210 & 29.0 & 202 & 28.2 & 202 & 28.4 & 0.003 \\
\hline
\end{tabular}

$\mathrm{n}$ : the number of participants detected as hypertension in each quintile 
Table 5 Adjusted odds ratio for hypertension across quintiles of dietary patterns in Diqing, Yunnan, China $(N=3591)$

\begin{tabular}{|c|c|c|c|}
\hline \multirow{2}{*}{$\begin{array}{l}\text { Dietary } \\
\text { patterns }\end{array}$} & Q1 & Q5 & \multirow[t]{2}{*}{$p$-value } \\
\hline & Adjusted OR (95\% Cl) & Adjusted OR (95\% Cl) & \\
\hline \multicolumn{4}{|c|}{ Grassland healthy } \\
\hline Model 1 & 1.000 (reference) & $0.693(0.537-0.893)$ & 0.005 \\
\hline Model 2 & 1.000(reference) & $0.703(0.535-0.924)$ & 0.012 \\
\hline \multicolumn{4}{|c|}{ Tuber and meat } \\
\hline Model 1 & 1.000(reference) & $0.678(0.530-0.868)$ & 0.002 \\
\hline Model 2 & 1.000 (reference) & $0.796(0.611-1.037)$ & 0.090 \\
\hline \multicolumn{4}{|c|}{ Fruit and vegetable } \\
\hline Model 1 & 1.000 (reference) & $0.759(0.593-0.970)$ & 0.028 \\
\hline Model 2 & 1.000 (reference) & $0.842(0.648-1.094)$ & 0.199 \\
\hline
\end{tabular}

Model 1: adjusted for sex, ethnicity, education level, BMI, physical activity and family history of hypertension

Model 2: model 1 additionally adjusted for age

dietary pattern named 'Fruit and vegetable' was correlated with high intake of fruit and vegetable in our study. As we know, fruits, vegetables, and low-fat dairy products which were characterized by Dietary Approaches to Stop Hypertension (DASH) pattern had been regarded as one of the most well-known dietary strategies for antihypertensive effect $[40,41]$. The negative association between this pattern and hypertension was appeared to be found, but the association was more likely to be explained by participants' age. When age was controlled, this inverse relationship disappeared. Even the 'Tuber and meat' dietary pattern and 'Fruit and vegetable' dietary pattern were not related to the lower prevalence of hypertension. It is also suggested that a healthy diet is an important strategy to prevent and control hypertension for us.

Additionally, the three dietary patterns also captured the socio-demographic characteristics of the study participants. Participants who were younger and had higher level of education adhered more to the 'Grassland healthy' pattern. High socioeconomic status assessed by higher education, purchasing power, or urban location was generally significantly associated with a healthy diet, which had been also reported in a systematic review [42]. The male, younger, Tibetan were more likely to involve in the 'Tuber and meat' pattern. As previously reported that the Tibetan had a preference for a special local diet of tsampa, butter tea, beef, and mutton [43]. Participants who were male, younger, Naxi and had lower level of education were more frequently involved in the 'Fruit and vegetable' pattern. Our finding revealed the individuality in minority's diets in China.

Nevertheless, the present study had several limitations. First, this study was cross-sectional in nature, thus the causal relationship between dietary patterns and hypertension could not be determined. Second, the semi-quantitative FFQ enabled us to capture more reliable information on participants' dietary patterns, but the recall bias could not be eliminated. Thirdly, the study participants were recruited from Diqing, southwest China, making a regional and ethnic representation. Therefore, it might not be generalized to other places and population.

\section{Conclusions}

In conclusion, our results indicate that 'Grassland healthy' dietary pattern is associated with lower risk of hypertension, providing an additional support for dietary intervention strategies to reduce the risk of hypertension among multi-ethnic populations. Considering the high prevalence of hypertension reported in this study, larger prospective studies are required to confirm our findings, and a scientific rationale for hypertension prevention is needed in Yunnan, especially in the economically depressed area.

\section{Additional file}

Additional file 1: Informed consent. (DOC $28 \mathrm{~kb}$ )

\section{Abbreviations}

95\% Cl: 95\% confidence interval; BMI: Body mass index; CDC: Centre for Disease Control and Prevention; DASH: Dietary Approaches to Stop Hypertension; DBP: Diastolic blood pressure; FFQ: Food frequency questionnaires; MET: Metabolic equivalents; OR: Odds ratio; SBP: Systolic blood pressure

\section{Acknowledgements}

We thank all the team members and all participants from three counties in Diqing for their assistance and support. We also acknowledged the department of public hygiene in disease control and prevention and People's hospital of Diqing for their important contribution to the data collection and consulting in this study.

\section{Funding}

This study was supported by public health projects of CDC in Diqing, Yunnan, southwest China.

\section{Availability of data and materials}

The datasets used during the present study are available from the corresponding author upon reasonable request.

\section{Authors' contributions}

$Y R$ conceived the analysis plan, analyzed the data and wrote the manuscript. $\mathrm{YH}, \mathrm{SQ}, \mathrm{XD}$ conducted this research and collected the data. QZ, YS involved in defining variables and developing analysis plan and providing some suggestions for writing the article. All authors read and approved the final manuscript, and they ensured the accuracy and integrity of this article.

\section{Ethics approval and consent to participate}

This observational study, data analysis and our manuscript were scientifically and ethically approved by the Centre for Disease Control and Prevention in Diqing. The approval was granted by Institutional Review Board at the Centre for Disease Control and Prevention in Diqing. Each participant with a unique code for individual differentiation provided a written informed consent before enrolment.

Consent for publication

Not applicable. 


\section{Competing interests}

The authors declare that they have no competing interests.

\section{Publisher's Note}

Springer Nature remains neutral with regard to jurisdictional claims in published maps and institutional affiliations.

\section{Author details}

Department of nutrition and food hygiene, Centre for Disease Control and Prevention (CDC), No.158 Dongsi Street, Kunming 650022, Yunnan, China. ${ }^{2}$ People's hospital of Diqing Tibetan Autonomous Prefecture, No. 19 Chicika Street, Shangri-la, Diqing 674400, Yunnan, China. ${ }^{3} \mathrm{CDC}$ of Diqing Tibetan Autonomous Prefecture, No. 88 Ren'an Road, Shangri-la, Diqing 674400, Yunnan, China.

\section{Received: 25 January 2018 Accepted: 30 August 2018}

\section{Published online: 10 September 2018}

\section{References}

1. Sarki AM, Nduka CU, Stranges S, Kandala N-B, Uthman OA. Prevalence of hypertension in low- and middle-income countries: a systematic review and meta-analysis. Medicine (Baltimore). 2015;94:e1959.

2. Irazola VE, Gutierrez L, Bloomfield G, Carrillo-Larco RM, Dorairaj P, et al. Hypertension prevalence, awareness, treatment, and control in selected LMIC communities: results from the NHLBI/UHG network of centers of excellence for chronic diseases. Glob Heart. 2016;11:47-59.

3. Kearney PM, Whelton M, Reynolds K, Muntner P, Whelton PK, et al. Global burden of hypertension: analysis of worldwide data. Lancet. 2005;365:217-23.

4. Li D, LV J, Liu F, Liu P, Yang X, et al. Hypertension burden and control in mainland China: analysis of nationwide data 2003-2012. Int J Cardiol. 2015; 184:637-44.

5. Kunes J, Zicha J. The interaction of genetic and environmental factors in the etiology of hypertension. Physiol Res. 2009;58(Suppl 2):33-41.

6. Falkner B. Hypertension in children and adolescents: epidemiology and natural history. Pediatr Nephrol. 2010;25:1219-24.

7. Eaton SB, Eaton SB. An evolutionary perspective on human physical activity: implications for health. Comp Biochem Physiol A Mol Integr Physiol. 2003; 136:153-9.

8. Hu FB. Dietary pattern analysis: a new direction in nutritional epidemiology. Curr Opin Lipidol. 2002;13:3-9.

9. Sabate J, Wien M. A perspective on vegetarian dietary patterns and risk of metabolic syndrome. Br J Nutr. 2015;113:S136-43.

10. Sun J, Buys NJ, Hills AP. Dietary pattern and its association with the prevalence of obesity, hypertension and other cardiovascular risk factors among Chinese older adults. Int J Environ Res Public Health. 2014;11:3956-71.

11. Du SF, Wang HJ, Zhang B, Zhai FY, Popkin BM. China in the period of transition from scarcity and extensive undernutrition to emerging nutritionrelated non-communicable diseases, 1949-1992. Obes Rev. 2014;15:8-15.

12. Zhai F, Fu D, Du S, Ge K, Chen C, et al. What is China doing in policymaking to push back the negative aspects of the nutrition transition? Public Health Nutr. 2002;5:269-73.

13. Batis C, Mendez MA, Gordon-Larsen P, Sotres-Alvarez D, Adair L, et al. Using both principal component analysis and reduced rank regression to study dietary patterns and diabetes in Chinese adults. Public Health Nutr. 2016:19:195-203.

14. Xu X, Hall J, Byles J, Shi Z, Dietary Pattern I. Associated with obesity in older people in China: data from China health and nutrition survey (CHNS). Nutrients. 2015;7:8170-88.

15. Shu L, Zheng PF, Zhang XY, Si CJ, Yu XL, et al. Association between Dietary Patterns and the Indicators of Obesity among Chinese: A Cross-Sectional Study. Nutrients. 2015:7:7995-8009.

16. Qin Y, Melse-Boonstra A, Pan X, Zhao J, Yuan B, et al. Association of dietary pattern and body weight with blood pressure in Jiangsu Province, China. BMC Public Health. 2014;14:948.

17. Jacobs DR, Tapsell LC. Food synergy: the key to a healthy diet. Proc Nutr Soc. 2013;72:200-6.

18. Le C, Zhankun S, Jun D, Keying Z. The economic burden of hypertension in rural south-West China. Tropical Med Int Health. 2012;17:1544-51.

19. Zheng PF, Shu L, Zhang XY, Si CJ, Yu XL, et al. Association between dietary patterns and the risk of hypertension among Chinese: a cross-sectional study. Nutrients. 2016:8:1-10.
20. Fan M, Lyu J, He P. Chinese guidelines for data processing and analysis concerning the international physical activity questionnaire. Zhonghua liu xing bing xue za zhi. 2014;35:961-4

21. Ma YQ, Mei WH, Yin $P$, Yang XH, Rastegar SK, et al. Prevalence of hypertension in Chinese cities: a meta-analysis of published studies. PLoS One. 2013;8:e58302

22. Li Y, Yang L, Yan J, Tang X, Xu X, et al. Prevalence, awareness, treatment, control and risk factors associated with hypertension among adults in southern China, 2013. PLoS One. 2016;11:e0146181.

23. Yang G, Ma Y, Wang S, Su Y, Rao W, et al. Prevalence and correlates of prehypertension and hypertension among adults in northeastern China: a cross-sectional study. Int J Environ Res Public Health. 2015;13:1.

24. Mingji C, Onakpoya IJ, Perera R, Ward AM, Heneghan CJ. Relationship between altitude and the prevalence of hypertension in Tibet: a systematic review. Heart. 2015;101:1054-60.

25. Yang S, Liu S, Wang Y, Wan H, Zhao D, et al. High blood pressure in Chinese ethnic minorities: report from rural Yunnan province. Am J Hypertens. 2011;24:1209-14.

26. Zhang X, Zhu M, Dib HH, Hu J, Tang S, et al. Knowledge, awareness, behavior (KAB) and control of hypertension among urban elderly in western China. Int J Cardiol. 2009;137:9-15.

27. Diaz KM, Shimbo D. Physical activity and the prevention of hypertension. Curr Hypertens Rep. 2013;15:659-68.

28. Xu T, Liu J, Zhu G, Liu J, Han S. Prevalence of prehypertension and associated risk factors among Chinese adults from a large-scale multi-ethnic population survey. BMC Public Health. 2016;16:775.

29. Wang D, He Y, Li Y, Luan D, Yang $X$, et al. Dietary patterns and hypertension among Chinese adults: a nationally representative cross-sectional study. BMC Public Health. 2011;11:925

30. Batis C, Sotres-Alvarez D, Gordon-Larsen P, Mendez MA, Adair L, et al. Longitudinal analysis of dietary patterns in Chinese adults from 1991 to 2009. Br J Nutr. 2014;111:1441-51.

31. Buendia JR, Li Y, Hu FB, Cabral HJ, Bradlee ML, et al. Regular yogurt intake and risk of cardiovascular disease among hypertensive adults. Am J Hypertens. 2018:31:557-65.

32. Teunissen-Beekman KF, Dopheide J, Geleijnse JM, Bakker SJ, Brink EJ, et al. Protein supplementation lowers blood pressure in overweight adults: effect of dietary proteins on blood pressure (PROPRES), a randomized trial. Am J Clin Nutr. 2012;95:966-71.

33. Wang Y, Shu Z, Sun F, Tao Q, Zhan S, et al. Dietary patterns and hypertension among adults in Taiwan. Journal Hyg Res. 2012;41:363-8.

34. Safdar NF, Bertone-Johnson ER, Cordeiro L, Jafar TH, Cohen NL. Dietary patterns and their association with hypertension among Pakistani urban adults. Asia Pac J Clin Nutr. 2015. https://doi.org/10.6133/apjen.2015.24.4.27.

35. Schwingshackl L, Schwedhelm C, Hoffmann G, Knuppel S, lqbal K, et al. Food groups and risk of hypertension: a systematic review and doseresponse meta-analysis of prospective studies. Adv Nutr. 2017;8:793-803.

36. Lee SA, Cai H, Yang G, Xu WH, Zheng W, et al. Dietary patterns and blood pressure among middle-aged and elderly Chinese men in shanghai. $\mathrm{Br}$ J Nutr. 2010;104:265-75.

37. Zhang Q, Chen X, Liu Z, Varma DS, Wan R, et al. Dietary patterns in relation to general and central obesity among adults in Southwest China. Int J Environ Res Public Health. 2016;13:11

38. Aleixandre A, Miguel M. Dietary fiber and blood pressure control. Food Funct. 2016:7:1864-71

39. Hartley L, May MD, Loveman E, Colquitt JL, Rees K. Dietary fibre for the primary prevention of cardiovascular disease. Cochrane Database Syst Rev. 2016. https://doi.org/10.1002/14651858.CD011472.pub2.

40. Al-Solaiman Y, Jesri A, Mountford WK, Lackland DT, Zhao Y, et al. DASH lowers blood pressure in obese hypertensives beyond potassium, magnesium and fibre. J Hum Hypertens. 2010:24:237-46.

41. Borgi L, Muraki I, Satija A, Willett WC, Rimm EB, et al. Fruit and vegetable consumption and the incidence of hypertension in three prospective cohort studies. Hypertension. 2016. https://doi.org/10.1161/HYPERTENSIONAHA.115.06497.

42. Mayen AL, Marques-Vidal P, Paccaud F, Bovet P, Stringhini S. Socioeconomic determinants of dietary patterns in low- and middle-income countries: a systematic review. Am J Clin Nutr. 2014;100:1520-31.

43. Xu S, Jiayong $\mathrm{Z}$, Li B, Zhu H, Chang $\mathrm{H}$, et al. Prevalence and clustering of cardiovascular disease risk factors among Tibetan adults in China: a population-based study. PLoS One. 2015;10:e0129966. 